GLS in our univariate study. Receiver operating characteristic curve analysis revealed hemoglobin as the best predictor for subclinical LVSD (AUC $=0.752$, $95 \% \mathrm{Cl}$ : 0.577-0.927, $P=.02)$ when compared to Age and $\mathrm{E} / \mathrm{A}$.

Conclusion: This prospective comparative study highlighted the diabetes mellitus and anemia burden on myocardial dysfunction in RA patients.

Disclosure of Interests: None declared

DOI: 10.1136/annrheumdis-2021-eular.3650

\section{AB0179 INFLUENCE OF AINFLUENCE OF ANTI- CITRULLINATED PROTEIN/PEPTIDE ANTIBODIES (ACPAS)ON ARTICULAR MANIFESTATIONS, DISEASE ACTIVITY AND STRUCTURAL SEVERITY IN ALGERIAN PATIENTS WITH EARLY RHEUMATOID ARTHRITIS}

F. Rahal $^{1}$, N. Brahumi ${ }^{2}$, A. Ladjouze-Rezig ${ }^{2}$, S. Lefkir ${ }^{1} .{ }^{1}$ Beni Messous University Hospital Center, Rheumatology, Algiers, Algeria; ${ }^{2}$ Ben Aknoun Hospital Center, Rheumatology, Algiers, Algeria

Background: Anti-citrullinated protein/peptide antibodies (ACPA) are highly specific and sensitive markers for rheumatoid arthritis (RA). There are also suggested to have a more severe rheumatoid arthritis.

Objectives: The aim of this study was to assess the influence of ACPA on disease activity, radiological severity, and functional disability in Algerian patient with early rheumatoid arthritis (RA)

Methods: Consecutive early RA patients (symptom duration $\leq 24$ months) recruited were included in the descriptive, longitudinal, prospective study. Demographic, biological, immunological and radiographic data were collected at the time of inclusion in the study. Disease activity as determined by the Disease Activity Score 28-CPR (DAS28- CPR: 4 variables), functional handicap as calculated by Heath Assessment Score (HAQ), and bone and joint damage as evaluated by Sharp-Van der Heijde (SVDH) erosion and narrowing score.

Results: One hundred and sixty-one patients with RA were recruited. Patients mean age $43.71 \pm 14$ years and mean symptom duration at inclusion was $10.48 \pm 7$ months. Small and larges were affected in $64,3 \%$. The mean ESR was $23,53 \pm 15,2 \mathrm{~mm} / 1$ st hour, and the mean CRP level was $19,42 \pm 39.8 \mathrm{mg} / \mathrm{l}$. Rheumatoid Factors (RFs) and Anti-Citrullinated Protein Antibodies (ACPAs) were present in $74 \%$ and $88 \%$ of patients, respectively. The presence of ACPAs was significantly associated with DAS28 $(p=0,004)$ and HAQ $(p=0,002)$. There was no significant difference in inflammatory markers and radiographic SVDH score between patients with and without ACPAs. Stepwise regression analysis showed that the presence of ACPAs was independently associated with localization when RA affected smalls and larges joint in the same time (OR=5,24; IC 95\% 1,22422,483; $p=0,026)$.

Conclusion: These data show that in patients with early RA, ACPAs positivity was significantly associated with articular manifestations, activity disease and functional handicap, but not with structural damage.

\section{REFERENCES:}

[1] Nikiphorou E, Norton S, Young A, et al. Association between rheumatoid arthritis disease activity, progression of functional limitation and longterm risk of orthopaedic surgery: combined analysis of two prospective cohorts supports EULAR treat to target DAS thresholds. Ann Rheum Dis. 2016;75(12):2080-2086. doi:10.1136/annrheumdis-2015-208669.

[2] Karimifar M, Salesi M, Farajzadegan Z. The association of anti-CCP1 antibodies with disease activity score 28 (DAS-28) in rheumatoid arthritis. Adv Biomed Res. 2012;1:30. doi:10.4103/2277-9175.98156.

[3] Boman A, Brink M, Lundquist A, et al. Antibodies against citrullinated peptides are associated with clinical and radiological outcomes in patients with early rheumatoid arthritis: a prospective longitudinal inception cohort study. RMD Open. 2019;5(2):e000946. Published 2019 Sep 3. doi:10.1136/ rmdopen-2019-000946.

Disclosure of Interests: None declared

DOI: 10.1136/annrheumdis-2021-eular.3657

\section{AB0180 \\ A MULTICENTER SELF-CONTROLLED CASE SERIES STUDY INVESTIGATING THE PREVENTIVE EFFECT OF SULFASALAZINE AGAINST PNEUMOCYSTIS PNEUMONIA}

T. Nunokawa ${ }^{1}$, T. Kakutani ${ }^{1}$, N. Chinen ${ }^{1}$, K. Shimada ${ }^{2}$, M. Kimura ${ }^{3}$, M. Tateishi ${ }^{3}$, F. Chen ${ }^{4}$, K. Setoguchi ${ }^{4}$, M. Sugihara ${ }^{5}{ }^{1}$ Tama Nambu Chiiki Hospital,
Department of Rheumatic Diseases, Tokyo, Japan; ${ }^{2}$ Tokyo Metropolitan Tama Medical Center, Department of Rheumatic Diseases, Tokyo, Japan; ${ }^{3}$ Tokyo Metropolitan Ohtsuka Hospital, Department of Rheumatology, Tokyo, Japan; ${ }^{4}$ Tokyo Metropolitan Cancer and Infectious Diseases Center Komagome Hospital, Department of Rheumatology, Tokyo, Japan; ${ }^{5}$ Tama-Hokubu Medical Center, Department of Rheumatic Diseases, Tokyo, Japan

Background: An animal study revealed that sulfasalazine (SSZ) enhances Pneumocystis clearance from the lung by accelerating macrophage activity.[1] Although the preventive effect of SSZ on Pneumocystis pneumonia (PCP) in patients with rheumatoid arthritis (RA) is reported in case-control studies, some important confounders might remain unmeasured and distort the results. [2-3] The self-controlled case series (SCCS) method involves only cases and controls fixed confounders automatically.[4]

Objectives: To evaluate the prophylactic effect of SSZ against PCP in patients with RA, controlling unmeasurable confounders by the SCCS method.

Methods: A retrospective study was conducted at five hospitals. Patients with RA who developed PCP between 2003 and 2019 were included. PCP was defined by the following criteria: (1) detection of Pneumocystis jirovecii in respiratory specimens by polymerase chain reaction; (2) clinical manifestations (pyrexia, dry cough, dyspnea, or hypoxia); (3) diffuse interstitial infiltrate on chest imaging; (4) absence of prophylaxis for PCP. Incidence rate ratio (IRR) for Pneumocystis pneumonia associated with sulfasalazine use was calculated by conditiona Poisson regression.

Results: We identified 48 episodes of PCP in 47 cases. Of these, $15(31.9 \%)$ died. Thirty received SSZ in certain periods of their observations (Table 1). While 46 episodes of PCP developed in the period of 168.9 person-years without SSZ use, only one episode of PCP developed in the period of 103.7 person-years with SSZ use. SSZ use had a decreased risk of PJP (adjusted IRR 0.007, 95\% $\mathrm{Cl}<0.001-0.067$ ) after adjusted for age group, the use of glucocorticoid, methotrexate, and tacrolimus, and the use of biologic agent or janus kinase inhibitor (Table 2)

Table 1. Characteristic of the $\mathbf{4 7}$ patients enrolled in the study.

Male/female, $\mathrm{n}(\%)$

Observational period (years), median (IQR)

Lung disease, $\mathrm{n}(\%)$

Use of sulfasalazine, $\mathrm{n}(\%)$

Outcome of PCP, death, $n(\%)$

Age at the onset of PCP (years), median (IQR)

$14(29.8) / 33(70.2)$ $72.0(66.3-79.1)$

$4.7(1.4-9.5)$

$23(48.9)$

$30(63.8)$

$15(31.9)$

PCP, Pneumocystis pneumonia; IQR, interquartile range.

Table 2. Unadjusted and adjusted incidence rate ratio for Pneumocystis pneumonia associated with sulfasalazine use.

\begin{tabular}{lllll}
\hline & $\begin{array}{l}\text { Observation length Episodes of PCP, Unadjusted IRR } \\
\text { (years) }\end{array}$ & $\mathrm{n}(\%)$ & $\begin{array}{l}\text { Adjusted IRR } \\
(\% \mathrm{Cl})\end{array}$ \\
\hline Use of SSZ & 103.7 & $1(2.1)$ & $0.010(0.001-0.092)$ & $\begin{array}{l}0.007(<0.001- \\
0.067) \\
\text { reference }\end{array}$ \\
\hline No use of SSZ & 168.9 & $47(97.9)$ & reference & .
\end{tabular}

IRR, incidence rate ratio; PCP, Pneumocystis pneumonia; SSZ, sulfasalazine.

Conclusion: Our study demonstrated the preventive effect of SSZ against PCP with confounders controlled by the SCCS.

\section{REFERENCES:}

[1] Wang, J., et al. Immune modulation with sulfasalazine attenuates immunopathogenesis but enhances macrophage- mediated fungal clearance during pneumocystis pneumonia. PLoS Pathog. 2010;19;6(8):e1001058.

[2] Nunokawa, T. et al. Prophylactic effect of sulfasalazine against Pneumocystis pneumonia in patients with rheumatoid arthritis: A nested case-control study. Semin. Arthritis Rheum. 2019;48(4):573-578.

[3] Nunokawa, T., et al. Effect of Sulfasalazine Use on the Presence of Pneumocystis Organisms in the Lung among Patients with Rheumatoid Arthritis: A Test-Negative Design Case-Control Study with PCR Tests. Mod. Rheumatol. 2019;29(3):436-440.

[4] Petersen, I., et al. Self controlled case series methods : an alternative to standard epidemiological study designs. BMJ. 2016;12;354:14515.

Disclosure of Interests: None declared

DOI: 10.1136/annrheumdis-2021-eular.3734 